\title{
Innate immune response in bovine neutrophils stimulated with Mycoplasma bovis
}

\author{
Satoshi Gondaira ${ }^{1}$, Koji Nishi ${ }^{1}$, Jumpei Fujiki ${ }^{2}$, Hidetomo Iwano ${ }^{2}$, Reina Watanabe ${ }^{1}$, Ayako Eguchi ${ }^{1}$, Yuki Hirano ${ }^{3}$,
} Hidetoshi Higuchi ${ }^{1^{*}}$ (D) and Hajime Nagahata ${ }^{1,4}$

\begin{abstract}
Mycoplasma bovis (M. bovis) is a significant worldwide pathogen of cattle. Neutrophils have an important role in the innate immune response during infection with $M$. bovis. However, even though neutrophils accumulate in M. bovis infection, the interaction of M. bovis and neutrophils has not been fully elucidated. We attempted to elucidate the innate immune response of neutrophils stimulated with $M$. bovis and evaluate the transcriptome and functional analysis of bovine neutrophils stimulated with M. bovis. Proinflammatory cytokines, such as inducible nitric oxide (iNOS), which was the most increased gene in transcriptome analysis, were increased in quantitative polymerase chain reaction analysis of bovine neutrophils stimulated with live or heat-killed $M$. bovis. Nitric oxide and intracellular reactive oxygen species production of neutrophils stimulated with M. bovis was significantly increased. Neutrophils stimulated with $M$. bovis showed an increased ratio of nonapoptotic cell death compared to unstimulated controls. We demonstrated that neutrophil extracellular traps (NETs) formation was not recognized in neutrophils stimulated with live $M$. bovis. However, heat-killed M. bovis induced NETs formation. We also showed the interaction with M. bovis and bovine neutrophils regarding proinflammatory cytokine gene expression and functional expression related to NETs formation. Live and killed M. bovis induced innate immune responses in neutrophils and had the potential to induce NETs formation, but live M. bovis escaped NETs.
\end{abstract}

Keywords: Mycoplasma bovis, Bovine, Neutrophils, Innate immune, Transcriptome analysis

\section{Introduction}

Mycoplasmas are classified under the class Mollicutes, which do not have a cell wall and are cause widespread infections of eukaryotes in nature [1]. Mycoplasma bovis (M. bovis) is a significant worldwide pathogen of cattle $[2,3]$ and is known to cause pneumonia, arthritis, and mastitis $[2,4]$, resulting in calf mortality, weight loss in surviving calves, and decreased milk production in dairy cows $[2,5]$, which all contribute to significant economic losses $[2,6]$.

\footnotetext{
*Correspondence: higuchi@rakuno.ac.jp

${ }^{1}$ Animal Health Laboratory, Department of Veterinary Medicine, School

of Veterinary Medicine, Rakuno Gakuen University, Ebetsu, Hokkaido 069-8501, Japan

Full list of author information is available at the end of the article
}

Neutrophils have an important role in infectious diseases at the front line. In M. bovis infection, neutrophils constitute the major accumulation of cells at an infection site [7]. M. bovis reportedly suppressed the production of reactive oxygen species (ROS) in the immune response of neutrophils [8]. ROS is the major innate immune factor of neutrophils to pathogens and is required for neutrophil extracellular traps (NETs) formation [9]. ROS and inducible nitric oxide (iNOS) are involved in the pathogenesis of Mycoplasma pneumoniae calves [10], and nitric oxide (NO) also triggers and enhances the release of NETs [11]. M. bovis was considered to escape the host immune response, and we previously reported that $M$. bovis escaped bovine NETs following the degradation of nucleic acid [12].

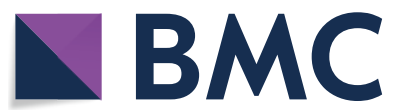

(c) The Author(s) 2021. This article is licensed under a Creative Commons Attribution 4.0 International License, which permits use, sharing, adaptation, distribution and reproduction in any medium or format, as long as you give appropriate credit to the original author(s) and the source, provide a link to the Creative Commons licence, and indicate if changes were made. The images or other third party material in this article are included in the article's Creative Commons licence, unless indicated otherwise in a credit line to the material. If material is not included in the article's Creative Commons licence and your intended use is not permitted by statutory regulation or exceeds the permitted use, you will need to obtain permission directly from the copyright holder. To view a copy of this licence, visit http://creativeco mmons.org/licenses/by/4.0/. The Creative Commons Public Domain Dedication waiver (http://creativecommons.org/publicdomain/ zero/1.0/) applies to the data made available in this article, unless otherwise stated in a credit line to the data. 
Inflammatory cytokines have an important role in the innate immune responses of neutrophils, such as recruitment, activation, and NETs formation [13]. The suppression of NO production and increased gene expression of inflammatory cytokines, such as IL-12 and TNF- $\alpha$, as a response of neutrophils to $M$. bovis, have been previously reported [14]. However, the mechanisms of the neutrophil immune response involved in $M$. bovis comprehensive gene expression have not been fully elucidated. We attempted to elucidate the innate immune response of neutrophils stimulated with $M$. bovis, determining gene expression related to the innate immune response through comprehensive gene expression analysis, and to determine whether $M$. bovis is capable of inducing NETs formation.

\section{Materials and methods Bacterial strains}

The bacterial strain used in this study was $M$. bovis (PG45: ATCC 25,523), grown in modified pleuropneumonia-like organisms (PPLO) medium (Kanto Kagaku, Tokyo, Japan) at $37{ }^{\circ} \mathrm{C}$ for 48 h. M. bovis was obtained by centrifugation (16 $000 \mathrm{~g}$ for $40 \mathrm{~min}$ ) and then washed with phosphate-buffered saline (PBS). The bacteria were then suspended in PBS to a cell density of $10^{8}$ colonyforming units per milliliter $(\mathrm{CFU} / \mathrm{mL})$, and the suspension was stored at $-70{ }^{\circ} \mathrm{C}$ until used.

\section{Bovine neutrophils}

Blood samples $(20 \mathrm{~mL})$ were collected in evacuation tubes containing sodium heparin (Terumo, Tokyo, Japan) from eleven clinically healthy primiparous Holstein cows in mid-lactation with no history of $M$. bovis infection. Three cows were used for microarray analysis and five cows were used for validation experiments using realtime PCR, detection of apoptotic cells, quantity of NO, and ROS production. Another three cows were used for the observation of NETs formation. The experimental protocol was approved by the Institutional Animal Care and Use Committee of Rakuno Gakuen University. Neutrophils were isolated by centrifugation on a Lympholyte device (Cedarlane, Ontario, Canada) according to the manufacturer's protocol. Cells were separated by centrifugation (300 $g$ for $30 \mathrm{~min}$ ), and neutrophils were transferred to a sterile tube (Becton Dickinson, Tokyo, Japan) and washed with cold PBS. Neutrophil viability was assessed using an AO/PI cell viability kit (Logos Biosystems, Gyeonggi, Korea) and Luna-FL (Logos Biosystems). Neutrophil ratios in polymorphonuclear leukocytes (PMNL) were obtained following Diff-Quick staining (Sysmex, Hyogo, Japan). Neutrophils were suspended in Hank's balanced salt solution or RPMI 1640 medium with L-glutamine (Sigma-Aldrich Corp., Tokyo,
Japan) and 10\% fetal bovine serum (FBS). Isolated neutrophils from five individual cows were used immediately. Neutrophils (concentration of $1 \times 10^{7}$ cells in $3 \mathrm{~mL}$ RPMI 1640 medium) were incubated in the presence of live or heat-killed $M$. bovis at a multiplicity of infection (MOI) of 1000:1 for 3 and $6 \mathrm{~h}$ at $37{ }^{\circ} \mathrm{C}$ and $5 \% \mathrm{CO}_{2}$ in 60-mm dishes (Asahi Glass, Tokyo, Japan). The number of bacteria in the milk of $M$. bovis mastitis was of $10^{9}$ to $10^{11} \mathrm{CFU}$ and the number of somatic cell counts was $10^{6}$ to $10^{7}$ cells $/ \mathrm{mL}$ [15]. Thus, MOI of 1000 is a sufficiently reasonable number of bacteria, taking into account the actual infection.

\section{RNA extraction}

Total RNA (TRNA) extracted from neutrophils was obtained using the PureLink RNA mini kit (Ambion, TX, USA). DNAse digestion was performed using TURBO DNA-free DNAse (Ambion). TRNA was quantified via spectrophotometry using a BioSpec-nano (Shimadzu, Kyoto, Japan). cDNA was synthesized from $1 \mu \mathrm{g}$ TRNA with ReverTra Ace reverse transcriptase (Toyobo, Osaka, Japan) and oligo dT primers (Toyobo). For each reaction, a parallel negative control reaction was performed in the absence of reverse transcriptase and analyzed via the $\beta$-actin band using polymerase chain reaction (PCR) and $1.5 \%$ agarose gels stained with ethidium bromide and visualized on an ultraviolet transilluminator.

\section{Microarray experiment and analysis}

Six microarray (three stimuli and three control) data for the neutrophils stimulated with $M$. bovis for $3 \mathrm{~h}$ were provided by Takara Bio, Inc. (Siga, Japan). The gene expression dataset was obtained using an Agilent singlecolor microarray platform $(4 \times 44 \mathrm{~K}$ bovine gene expression array, grid ID 023,647). Samples were processed for Agilent microarrays, and data were normalized as described previously [16]. We used $t$-tests to identify significant gene expression differences $(P<0.025)$ between samples. In a further filtering step, we selected only genes with a fold change of $\geq 2$. The gene annotation used was bioDBnet [17]. Heat map analysis was done using $\mathrm{R}$ version 3.6.1, and gene ontology enrichment was done using the BioMart enrichment tool [18]. The whole dataset is available publicly from the ArrayExpress database (accession number E-MTAB-9022).

\section{Quantitative reverse transcription PCR (qPCR) analysis}

The reaction was performed using a Thunderbird SYBR qPCR mix (Toyobo) and a CFX real-time PCR system (Bio-Rad Laboratories, Hercules, CA, USA). Information on the primers is depicted in Additional file 1. We used the melting curve analysis to evaluate each primer pair for specificity to ascertain that only one product 
was amplified. We performed a Basic Logical Alignment Search Tool (BLAST) search to confirm that the primer sequences amplified only the target gene of interest. Thermal cycling consisted of initial denaturation at $95{ }^{\circ} \mathrm{C}$ for $5 \mathrm{~min}$, followed by 40 cycles of denaturation at $95{ }^{\circ} \mathrm{C}$ for $15 \mathrm{~s}$, annealing at $60{ }^{\circ} \mathrm{C}$ for $30 \mathrm{~s}$, and extension at $72{ }^{\circ} \mathrm{C}$ for $30 \mathrm{~s}$. The melting temperature of the PCR product was determined by melting curve analysis, which was performed by heating the PCR product from $55^{\circ} \mathrm{C}$ to $95{ }^{\circ} \mathrm{C}$ and monitoring the fluorescence change every $0.5{ }^{\circ} \mathrm{C}$. $\beta$-actin, glyceraldehyde-3-phosphate dehydrogenase $(G A P D H)$, and tryptophan 5-monooxygenase activation protein zeta polypeptide (YWHAZ) were used as reference genes $[19,20]$.

\section{Detection of apoptotic cells and quantity of NO and ROS production}

To evaluate NO production and the ratio of apoptosis cells in neutrophils stimulated with $M$. bovis, neutrophils $\left(2 \times 10^{5}\right.$ cells/200 $\mu \mathrm{L}$ RPMI 1640 medium in 96-well tissue culture plates) were incubated in the presence of live M. bovis at an MOI of $1000(10 \mu \mathrm{L})$ for 1,3 , and $6 \mathrm{~h}$ at $37{ }^{\circ} \mathrm{C}$ and under $5 \% \mathrm{CO}_{2}$. The $\mathrm{NO}$ production and ratio of apoptosis cell were measured using a Muse NO kit or Muse Annexin V and dead cell kit (Millipore, Darmstadt, Germany) and Muse cell analyzer (Millipore) according to the manufacturer's protocol. To measure the quantity of intracellular ROS in neutrophils stimulated with $M$. bovis, neutrophils $\left(2 \times 10^{5}\right.$ cells $/ 1 \mathrm{~mL}$ RPMI 1640 medium in a $3 \mathrm{~cm}$ dish) were stimulated with $10 \mu \mathrm{L}$ conteining live M. bovis and/or phorbol myristate acetate (PMA; SigmaAldrich Corp.) or PBS for control at an MOI of 1000 for $30 \mathrm{~min}$ at $37^{\circ} \mathrm{C}$ and $5 \% \mathrm{CO}_{2}$. After that, intracellular ROS production was detected using the Muse Oxidative stress kit and Muse cell analyzer (Millipore) according to the manufacturer's protocol.

\section{Observation of NETs formation}

Neutrophils (concentration of $1 \times 10^{6}$ cells suspended in $100 \mu \mathrm{L}$ RPMI medium with $10 \%$ FBS) were seeded onto glass coverslips treated with $0.001 \%$ poly-l-lysine (Matsunami glass, Tokyo, Japan) and placed in a $35 \mathrm{~mm}$ dish (Iwaki, Shizuoka, Japan). Cells were incubated for $1 \mathrm{~h}$ at $37{ }^{\circ} \mathrm{C}$ in $5 \% \mathrm{CO}_{2}$. Neutrophils were incubated with PMA for 30 min to induce NETs formation (or with PBS for control), and then, $10^{7} \mathrm{CFU}$ octadecyl rhodamine $\mathrm{B}$ chloride (Sigma-Aldrich Corp.) labeled live or heat-killed $M$. bovis (or with PBS for control) were added and incubated for $30 \mathrm{~min}$ at $37{ }^{\circ} \mathrm{C}$ under a $5 \% \mathrm{CO}_{2}$. Neutrophils were washed with PBS and stained with 4,6-diamidino2-phenylindole, dilactate (DAPI) for 15 min (Dojindo, Tokyo, Japan). Coverslips were washed with PBS, coated with Fluoromount (Diagnostic Biosystems, Pleasanton,
CA, USA), and viewed using a fluorescence microscope (Nikon, Tokyo, Japan). Three bovine neutrophil studies were performed individually.

\section{Statistical analysis}

Data from five cows were expressed as mean \pm standard error (SE). The Kruskal-Wallis test was performed for comparison between groups, Steel test for multiple comparisons, and Welch's $t$-test for paired groups using Ekuseru-Toukei 2010 for Windows (Social Survey Research Information, Tokyo, Japan). In all cases, $P<0.05$ was considered statistically significant.

\section{Results}

\section{Microarray analysis}

We investigated gene expression in neutrophils stimulated with live $M$. bovis using an Agilent Bovine Gene Expression Microarray. Statistical analysis revealed that 61 genes in neutrophils stimulated with live $M$. bovis were significantly increased and 30 significantly decreased $(P<0.025$ with $>$ twofold increase $)$ compared to unstimulated neutrophils (Figure 1A and Additional file 3). Expression gene patterns with significant differences were visualized using a heat map (Figure 1B). The $M$. bovis stimulated and unstimulated groups showed similar expression patterns. The gene set related to function did not significantly recognize change, but that of the immune system and carbohydrate metabolic processes were increased (Figure $1 \mathrm{C}$ and Additional file 2). To validate these results, genes related to the immune system were quantified using real-time PCR (Figure 2). Inducible NO synthase (iNOS), interleukin 36A (IL-36A), chemokine $\mathrm{C}-\mathrm{X}-\mathrm{C}$ motif ligand 2 (CXCL2), and signaling lymphocytic activation molecule (SLAM) family member 7 (SLAMF7) mRNA expression in neutrophils after $3 \mathrm{~h}$ of stimulation with $M$. bovis were significantly $(P<0.01)$ increased compared to unstimulated controls. Basic leucine zipper transcription factor ATF-like (BATF) and SLAM family member 1 (SLAMF1) mRNA expression also were significantly increased $(P<0.05)$. $\mathrm{C}-\mathrm{C}$ motif chemokine ligand 24 (CCL24) was significantly decreased $(P<0.01)$ compared to unstimulated controls.

\section{Quantification of proinflammatory cytokine mRNA expression}

Expression of proinflammatory cytokine, IL-1 $\beta$, IL-6, tumor necrosis factor $\alpha$ (TNF- $\alpha$ ), IL-8, IL-12, and interferon $\gamma($ IFN- $\gamma$ ) mRNA in neutrophils stimulated with live or heat-killed $M$. bovis at 3 and $6 \mathrm{~h}$ was evaluated by qPCR (Figure 3). These cytokines showing mRNA expression in neutrophils stimulated with live $M$. bovis for $3 \mathrm{~h}$ were significantly (IL-1 $\beta$ and IL-12, $P<0.05$; TNF- $\alpha$ and IL-8, $P<0.01)$ increased compared to 

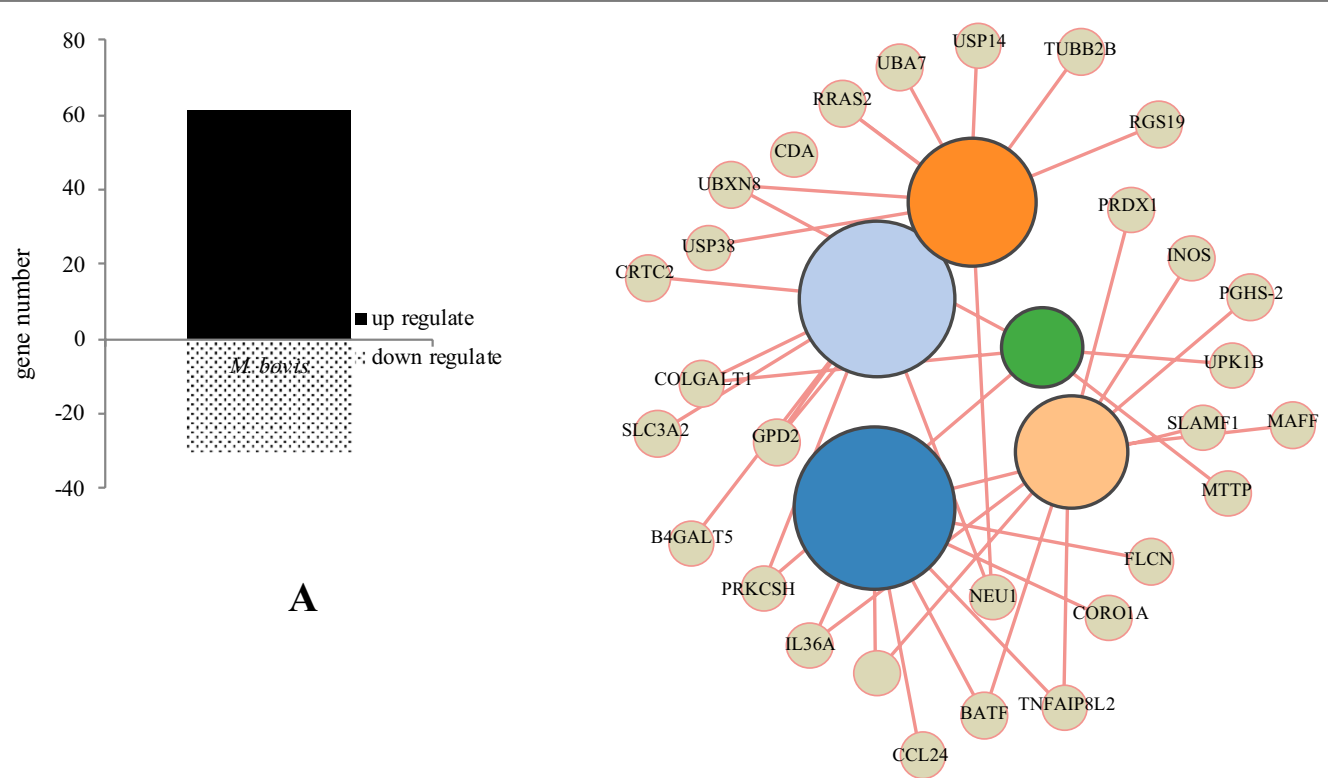

A
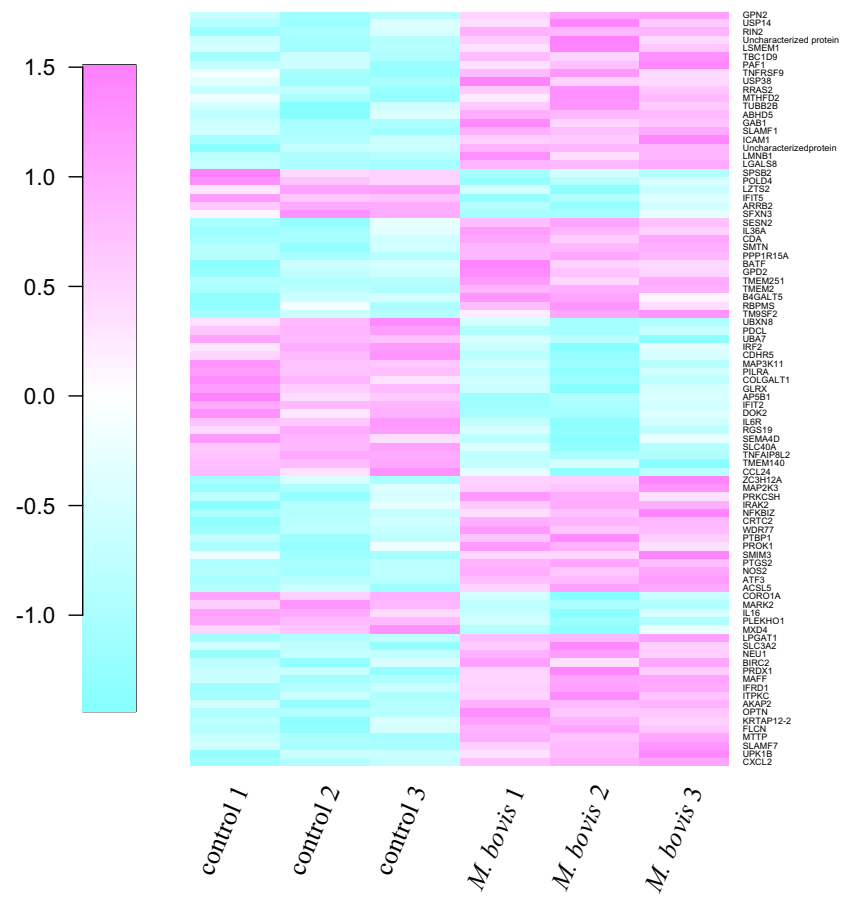

immune system process

carbohydrate metabolic process

catabolic process

response to stress

endoplasmic reticulum

\section{C}

\section{B}

Figure 1 Microarray analysis in neutrophils stimulated with $\boldsymbol{M}$. bovis. Bovine neutrophils were evaluated at $3 \mathrm{~h}$ after stimulation with $M$. bovis in three cows. A Number of significantly ( $t$-tests, $P<0.025$ and $\geq$ twofold change) downregulated or upregulated mRNA. B Heat map analysis of genes with significantly ( $t$-tests, $P<0.025$ and $\geq$ twofold change) different gene expression levels by microarray analysis in neutrophils stimulated with $M$. bovis. C Gene ontology enrichment analysis of genes with significantly ( $t$-tests, $P<0.025$ and $\geq$ twofold change) different gene expression levels by microarray analysis in neutrophils stimulated with $M$. bovis. 


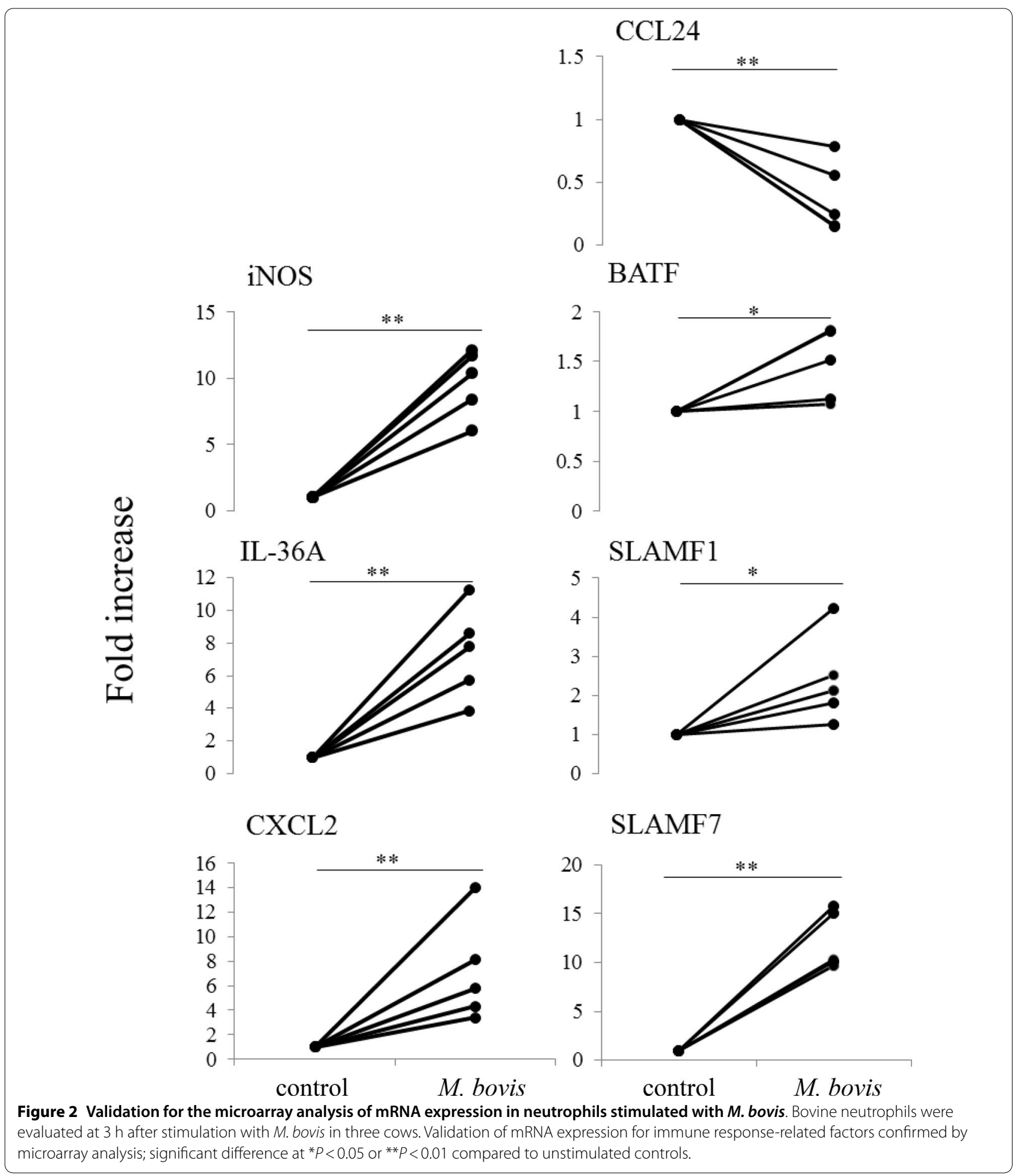




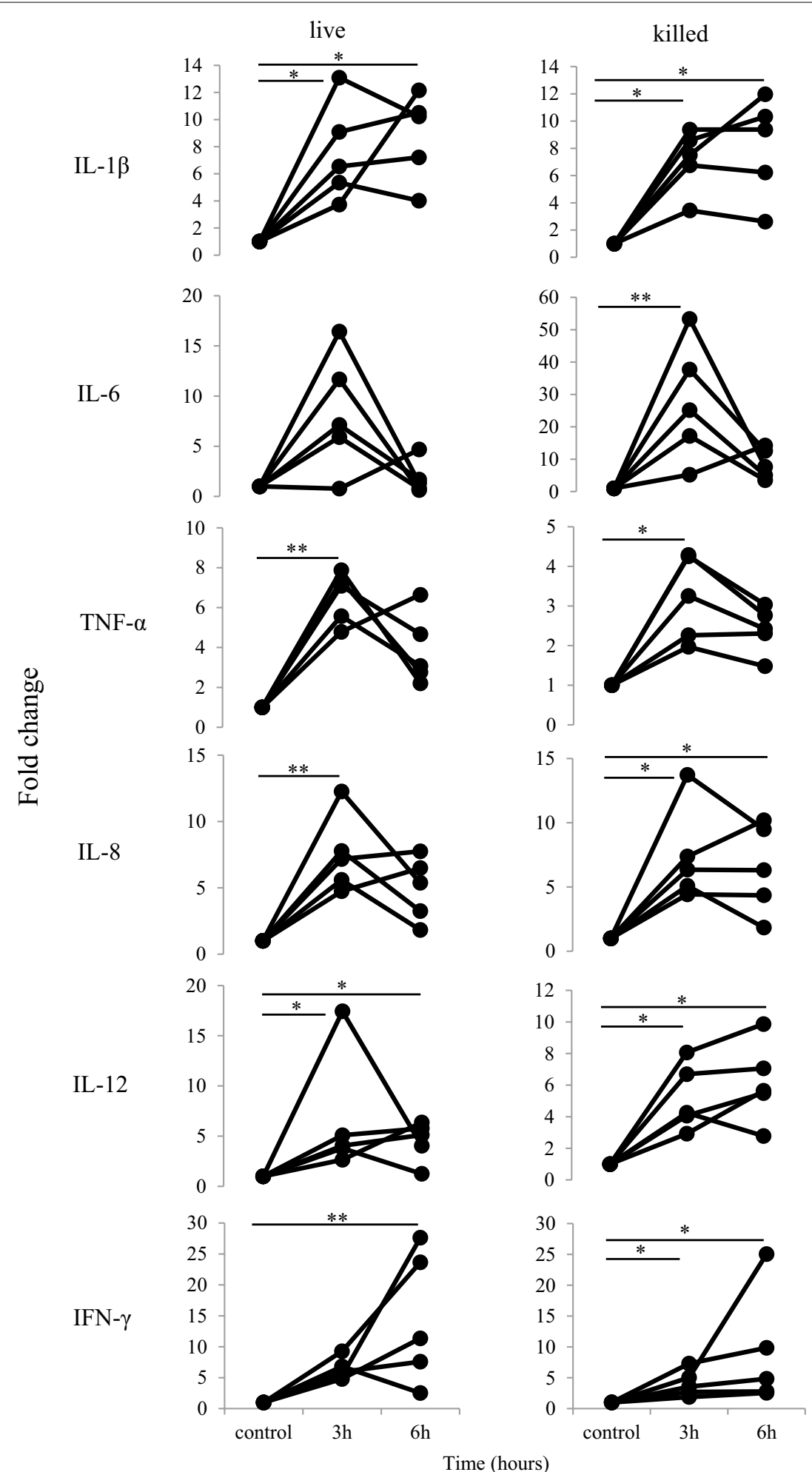

Figure 3 mRNA expression of proinflammatory cytokine related genes after stimulation with $\boldsymbol{M}$. bovis. Bovine neutrophils were evaluated at 3 or $6 \mathrm{~h}$ after stimulation with live or heat-killed M. bovis in five cows. The mRNA expression of IL-1 $\beta, I L-6$, TNF- $a, I L-8, I L-12$, and IFN- $\gamma$ was determined by $\mathrm{qPCR}$ and expressed as a fold increase, as described in the Materials and methods. The data were expressed in five cows; significant difference at ${ }^{*} P<0.05$ or ${ }^{* *} P<0.01$ compared to unstimulated controls. 


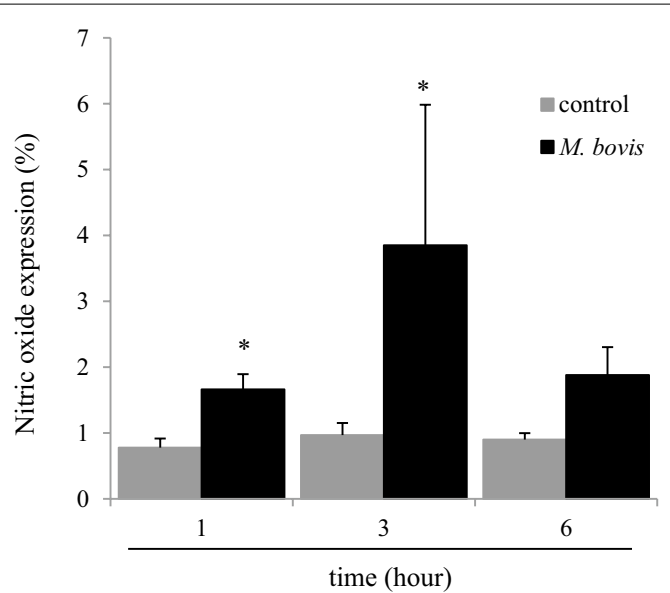

A

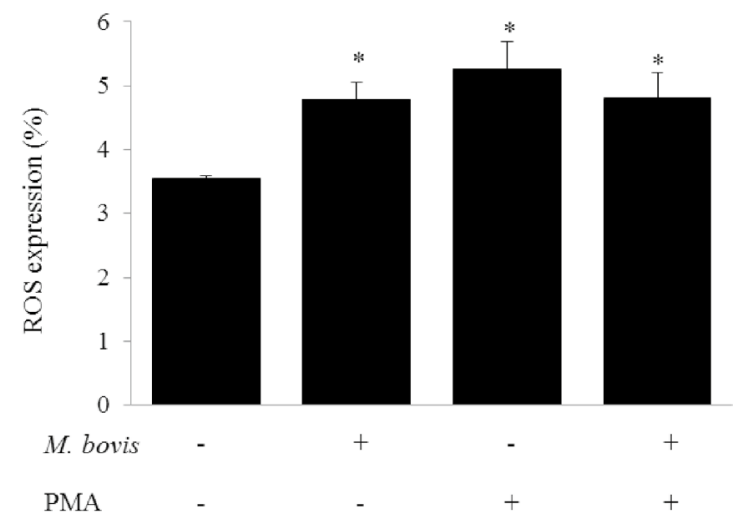

B

Figure 4 Quantity of NO and ROS production in neutrophils stimulated with $\boldsymbol{M}$. bovis. A Bovine neutrophils were evaluated at 1, 3, and $6 \mathrm{~h}$ after stimulation with M. bovis in five cows. The ratio of NO production cells is shown. Data were expressed as means \pm SE in five cows; significant difference at ${ }^{*} P<0.05$ compared to unstimulated controls. B Neutrophils were incubated with M. bovis (MOI of 1000) and/or PMA for 30 min. The ratio of ROS production cells is shown. Data were expressed as means \pm SE of five cows; significant difference at $* P<0.05$ compared to unstimulated controls.

unstimulated cells as were those stimulated with heatkilled $M$. bovis (IL-1 $\beta$, TNF- $\alpha$, IL-8, IL-12, and IFN- $\gamma$, $P<0.05$; IL-6, $P<0.01$ ). After $6 \mathrm{~h}$ of stimulation with $M$. bovis, IL-1 $\beta$ (live and heat-killed, $P<0.05$ ), IL-8 (heatkilled, $P<0.05$ ), IL-12 (live and heat-killed, $P<0.05$ ), and IFN- $\gamma$ (live, $P<0.01$, and heat-killed, $P<0.05$ ) demonstrated significantly increased mRNA expression in neutrophils. 


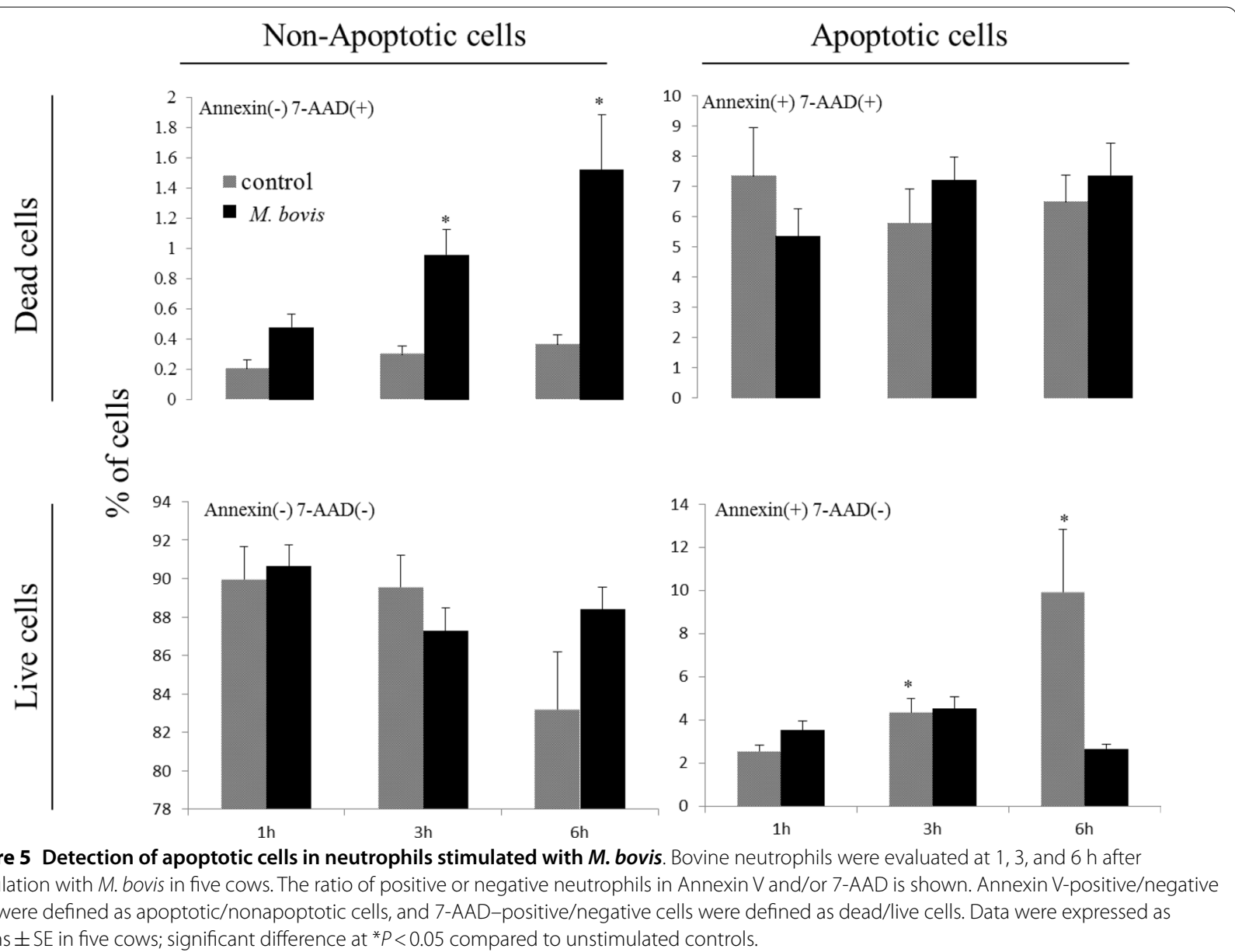

\section{Evaluation producing NO and intracellular ROS} of neutrophils stimulated with $M$. bovis

NO production of neutrophils stimulated with $M$. bovis was significantly increased $(P<0.05)$ at 1 and $3 \mathrm{~h}$ compared to controls (Figure 4A). Intracellular ROS production of neutrophils stimulated with $M$. bovis, M. bovis and PMA, or PMA was significantly increased $(P<0.05)$ compared to unstimulated controls (Figure 4B).
Evaluation of the apoptotic, nonapoptotic, dead, or live cells stimulated with $M$. bovis

The ratio of apoptotic cells in neutrophils stimulated with $M$. bovis at an MOI of 1000 for 1,3 , and $6 \mathrm{~h}$ is shown Figure 5. The ratios of Annexin-positive and 7-AADnegative cells (early apoptosis) in bovine neutrophils was significantly increased $(P<0.05)$ at $3(4.36 \%)$ and 6 (9.92\%) h compared to that at $1 \mathrm{~h}(2.54 \%)$. The ratios of Annexin-negative and 7-AAD-positive cells (dead cells other than nonapoptotic cells) in bovine neutrophils stimulated with $M$. bovis were significantly increased 


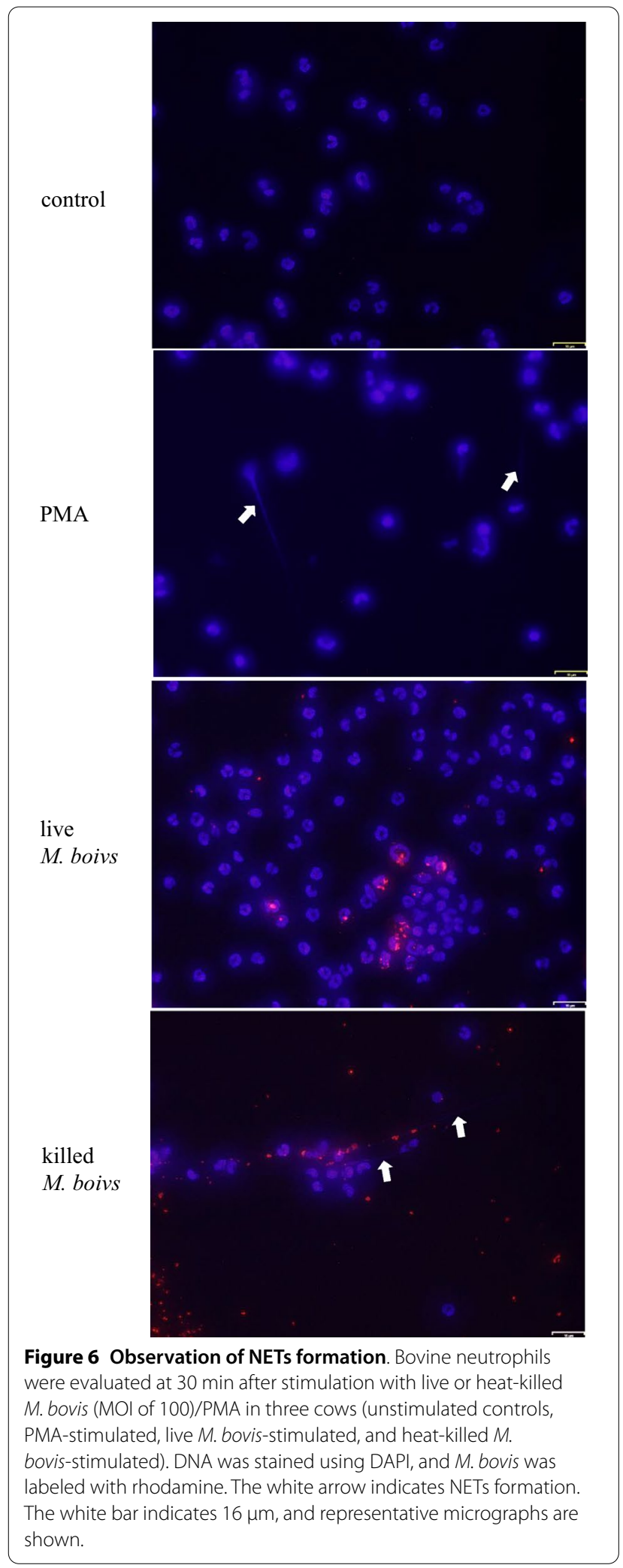

$(P<0.05)$ at $3(0.96 \%)$ and $6(1.52 \%)$ h compared to that at $1 \mathrm{~h}(0.20 \%)$. The ratios of Annexin-negative and 7-AADnegative cells (live cells) in nonstimulated cells tended to decrease in a time-dependent manner, and those of Annexin-positive and 7-AAD-positive cells (late apoptotic and necrotic cells) in neutrophils stimulated with $M$. bovis tended to increase in a time-dependent manner.

\section{Observation of NETs formation}

NETs formation in neutrophils stimulated with live or heat-killed M. bovis is shown in Figure 6. NETs formation was detected in neutrophils stimulated with PMA as an inducer of NETs formation, whereas it was not observed in neutrophils stimulated with live $M$. bovis and unstimulated controls. However, in neutrophils stimulated with heat-killed M. bovis, NETs formation was recognized, and $M$. bovis was localized to be on NETs.

\section{Discussion}

We studied the innate immunity of bovine neutrophils to $M$. bovis, and we especially reported a transcriptome analysis of bovine neutrophils stimulated with $M$. bovis and its immune-related functional analysis. Proinflammatory cytokines, such as iNOS, IL-36A, and CXCL2 mRNA, were increased in neutrophils stimulated with $M$. bovis as determined in the transcriptome analysis using microarray and qPCR for validation. iNOS induced NO production with antibacterial activity and was related to the formation of NETs [11]. Previous studies [14] did not show the production of neutrophil NO upon $M$. bovis stimulation, which may be due to the use of different MOIs and detection methods. CXCL2 is a chemokine related to priming of neutrophils [21] and enhanced antibacterial activity [22]. SLAMF1 and SLAMF7 affect the development of $\mathrm{T}$ cells [23]. BATF was reported to regulate $\mathrm{T}$ and $\mathrm{B}$ lymphocytes in immune response and differentiation [24]. IL-1 $\beta, I L-6$, and $T N F-\alpha$ are known rapid transcription-genes, proinflammatory cytokines, and the peak time point in these genes was mainly $3 \mathrm{~h}$. IL-1 $\beta$ - and IL-8-related migration and activation of neutrophils reportedly had an important role in maintaining inflammation in $M$. bovis infectious diseases. IL-12 and IFN- $\gamma$ mainly reached peak levels at $6 \mathrm{~h}$ after stimulation with $M$. bovis, which may be due to the activated neutrophils and a type 1 immune response [25]. The production of IL-12 and TNF- $\alpha$ by M. bovis-stimulated neutrophils has been also observed in a previous study [14], which is in line with our present results. In gene ontology enrichment analysis, most dynamically changed genes indicated an immune response, and $M$. bovis induced an innate immune response in bovine neutrophils. The carbohydrate metabolic process was the second largest gene set changed, and it includes the production of activated 
oxygen. Activated oxygen production in neutrophils stimulated with $M$. bovis was not recognized as reported previously $[26,27]$. However, this study demonstrated that intracellular production of activated oxygen was recognized. Mycoplasma species were known to have a resistance factor for activated oxygen [28, 29], which suggested that, although neutrophils stimulated with $M$. bovis produced activated oxygen, $M$. bovis attenuated extracellular activated oxygen. Because ROS were required for NETs formation [9], M. bovis may have potential in inducing NETs formation. However, as ROS-independent NETs formation has been reported recently [30, 31], further studies are needed on $M$. bovis-induced ROS production. The production of NO in neutrophils reportedly contributed to NETs formation [11]. In our study, neutrophils stimulated with $M$. bovis in transcriptome analysis and qPCR analysis showed increased iNOS mRNA expression, and NO production was increased in neutrophils stimulated with $M$. bovis. It had been reported that iNOS was strongly expressed in lungs of calves with coagulative and caseous necrosis lesion after infection with M. bovis [10]. Thus, it was suggested that the immune response of neutrophils was involved in the pathogenesis in mycoplasma infectious disease. Neutrophils stimulated with $M$. bovis showed an increased ratio of nonapoptotic cell death compared to unstimulated controls. It was considered that NETosis, which is cell death following NETs formation, contributed to nonapoptotic cell death. Mulongo et al. [32] and Maina et al. [33] reported that M. bovis delayed the apoptosis of monocytes and macrophages, respectively. Instead of suppressing apoptosis in neutrophils, M. bovis may promote NETs formation. In the study by Jimbo et al., the production of elastase, which is used as an index of NETs, was observed from neutrophils under stimulation with live M. bovis [14]. NETs formation was not observed in live bacteria stimulation, but it was observed in heat-killed bacteria stimulation. This result cannot immediately indicate that $M$. bovis has not induced NETs formation. This suggested that NETs were degraded by $M$. bovis nuclease in live bacteria as reported previously [26, 27], whereas in heat-killed $M$. bovis, the nuclease was inactivated by heat treatment and thus NETs formation was observed. The increased expression of proinflammatory cytokine mRNA even after stimulation with heat-killed bacteria suggested that $M$. bovis has the potential to induce NETs formation even in killed bacteria.

In conclusion, we demonstrated the innate immune response gene expression of bovine neutrophils stimulated with $M$. bovis, its related function expression related to NETs formation, and interaction between $M$. bovis and bovine neutrophils.

\section{Abbreviations}

M. bovis: Mycoplasma bovis; iNOS: Inducible nitric oxide; NETs: Neutrophil extracellular traps; ROS: Reactive oxygen species; PPLO: Pleuropneumonia-like organisms; PBS: Phosphate-buffered saline; CFU/mL: Colony-forming units per milliliter; FBS: Fetal bovine serum; MOI: Multiplicity of infection; TRNA: Total RNA; GAPDH: Glyceraldehyde-3-phosphate dehydrogenase; YWHAZ: Tryptophan 5-monooxygenase activation protein zeta polypeptide ; DAPI: 4,6-Diamidino-2-phenylindole, dilactate ; IL-36A: Interleukin 36A; CXCL2: Chemokine C-X-C motif ligand 2 ; SLAMF7: Signaling lymphocytic activation molecule family member 7; BATF: Basic leucine zipper transcription factor ATFlike; SLAMF1: Signaling lymphocytic activation molecule family member 1 ; CCL24: C-C motif chemokine ligand 24; TNF-a: Tumor necrosis factor a; IFN- $\gamma$ : Interferon $\gamma$.

\section{Supplementary Information}

The online version contains supplementary material available at https://doi. org/10.1186/s13567-021-00920-2.

\section{Additional file 1. Sequences of oligonucleotide primers.}

Additional file 2. The biological process GO term enrichment in bovine neutrophils stimulated with $M$. bovis. "Corrected P-Value" is correction for multiple testing.

Additional file 3. Transcriptome analysis in neutrophils stimulated with $\boldsymbol{M}$. bovis. Bovine neutrophils were evaluated by microarray analysis at $3 \mathrm{~h}$ after stimulation with $M$. bovis in three cows. After normalization and gene annotation, fluorescence intensity in significantly ( $t$-tests, $P<0.025$ and $a \geq$ twofold change) upregulated or downregulated genes was shown for each cow (control as unstimulated control vs. Mb as $M$. bovis stimulation).

\section{Acknowledgements}

The authors would like to thank Enago for the English language review.

\section{Authors' contributions}

Conceived and designed this study: SG, HI, JF, HH and HN. Performed the experiments: SG, KN, JF, RW, AE and YH. Conducted the data analysis: SG. Wrote the paper: SG and HH. All authors read and approved the final manuscript.

\section{Funding}

The authors have not declared a funding from any public or commercial agency.

Availability of data and materials

All datasets are presented in the paper or additional files supporting the manuscript.

\section{Declarations}

\section{Ethics approval and consent to participate}

Animal experiments were approved by the Institutional Animal Care and Use Committee of Rakuno Gakuen University (VH24A4).

\section{Competing interests}

The authors declare that they have no competing interests.

\footnotetext{
Author details

${ }^{1}$ Animal Health Laboratory, Department of Veterinary Medicine, School of Veterinary Medicine, Rakuno Gakuen University, Ebetsu, Hokkaido 069-8501, Japan. ${ }^{2}$ Veterinary Biochemistry, Department of Veterinary Medicine, School of Veterinary Medicine, Rakuno Gakuen University, Ebetsu, Hokkaido 069-8501, Japan. ${ }^{3}$ Animal Research Center, Agricultural Research Department, Hokkaido Research Organization, Shintoku, Hokkaido 081-0038, Japan. ${ }^{4}$ Farm Animal Veterinary Nursing Laboratory, Department of Veterinary Associated Science, Faculty of Veterinary Medicine, Okayama University, Imabari, Ehime 794-8555, Japan.
} 
Received: 4 August 2020 Accepted: 28 February 2021

Published online: 16 April 2021

\section{References}

1. Razin S, Yogev D, Naot Y (1998) Molecular biology and pathogenicity of mycoplasmas. Microbiol Mol Biol Rev 62:1094-1156

2. Maunsell FP, Woolums AR, Francoz D, Rosenbusch RF, Step DL, Wilson DJ, Janzen ED (2011) Mycoplasma bovis infections in cattle. J Vet Intern Med 25:772-783

3. Nicholas RA (2011) Bovine mycoplasmosis: silent and deadly. Vet Rec 168:459-462

4. Fox LK (2012) Mycoplasma mastitis: causes, transmission, and control. Vet Clin North Am Food Anim Pract 28:225-237

5. Pfützner H, Sachse K (1996) Mycoplasma bovis as an agent of mastitis, pneumonia, arthritis and genital disorders in cattle. Rev Sci Tech 15:1477-1494

6. Hertl JA, Schukken YH, Welcome FL, Tauer LW, Gröhn YT (2014) Pathogenspecific effects on milk yield in repeated clinical mastitis episodes in Holstein dairy cows. J Dairy Sci 97:1465-1480

7. Khodakaram-Tafti A, López A (2004) Immunohistopathological findings in the lungs of calves naturally infected with Mycoplasma bovis. J Vet Med A Physiol Pathol Clin Med 51:10-14

8. Wiggins MC, Woolums AR, Hurley DJ, Sanchez S, Ensley DT, Donovan D (2011) The effect of various Mycoplasma bovis isolates on bovine leukocyte responses. Comp Immunol Microbiol Infect Dis 34:49-54

9. Fuchs TA, Abed U, Goosmann C, Hurwitz R, Schulze I, Wahn V, Weinrauch Y, Brinkmann V, Zychlinsky A (2007) Novel cell death program leads to neutrophil extracellular traps. J Cell Biol 176:231-241

10. Hermeyer K, Jacobsen B, Spergser J, Rosengarten R, Hewicker-Trautwein M (2011) Detection of Mycoplasma bovis by in-situ hybridization and expression of inducible nitric oxide synthase, nitrotyrosine and manganese superoxide dismutase in the lungs of experimentally-infected calves. J Comp Pathol 145:240-250

11. Manda-Handzlik A, Bystrzycka W, Cieloch A, Glodkowska-Mrowka E, Jankowska-Steifer E, Heropolitanska-Pliszka E, Skrobot A, Muchowicz A, Ciepiela O, Wachowska M, Demkow U (2020) Nitric oxide and peroxynitrite trigger and enhance release of neutrophil extracellular traps. Cell Mol Life Sci 77:3059-3075

12. Gondaira S, Higuchi H, Iwano H, Nakajima K, Kawai K, Hashiguchi S, Konnai S, Nagahata H (2015) Cytokine mRNA profiling and the proliferative response of bovine peripheral blood mononuclear cells to Mycoplasma bovis. Vet Immunol Immunopathol 165:45-53

13. Brinkmann V, Reichard U, Goosmann C, Fauler B, Uhlemann Y, Weiss DS, Weinrauch Y, Zychlinsky A (2004) Neutrophil extracellular traps kill bacteria. Science 303:1532-1535

14. Jimbo S, Suleman M, Maina T, Prysliak T, Mulongo M, Perez-Casal J (2017) Effect of Mycoplasma bovis on bovine neutrophils. Vet Immunol Immunopathol 188:27-33

15. Gondaira S, Nishi K, Tanaka T, Yamamoto T, Nebu T, Watanabe R, Konnai S, Hayashi T, Kiku Y, Okamoto M, Matsuda K, Koiwa M, Iwano H, Nagahata H, Higuchi $H$ (2020) Immunosuppression in cows following intramammary infusion of Mycoplasma bovis. Infect Immun 88:e00521-e619

16. Chain B, Bowen H, Hammond J, Posch W, Rasaiyaah J, Tsang J, Noursadeghi M (2010) Error, reproducibility and sensitivity: a pipeline for data processing of Agilent oligonucleotide expression arrays. BMC Bioinformat 11:344

17. Mudunuri U, Che A, Yi M, Stephens RM (2009) bioDBnet: the biological database network. Bioinformat 25:555-556

18. Smedley D, Haider S, Durinck S, Pandini L, Provero P, Allen J, Arnaiz O, Awedh MH, Baldock R, Barbiera G, Bardou P, Beck T, Blake A, Bonierbale M, Brookes AJ, Bucci G, Buetti I, Burge S, Cabau C, Carlson JW, Chelala
C, Chrysostomou C, Cittaro D, Collin O, Cordova R, Cutts RJ, Dassi E, Di Genova A, Djari A, Esposito A, Estrella H, Eyras E, Fernandez-Banet J, Forbes S, Free RC, Fujisawa T, Gadaleta E, Garcia-Manteiga JM, Goodstein D, Gray K, Guerra-Assunção JA, Haggarty B, Han DJ, Han BW, Harris T, Harshbarger J, Hastings RK, Hayes RD, Hoede C, Hu S et al (2015) The BioMart community portal: an innovative alternative to large, centralized data repositories. Nucleic Acids Res 43:W589-W598

19. Robinson TL, Sutherland IA, Sutherland J (2007) Validation of candidate bovine reference genes for use with real-time PCR. Vet Immunol Immunopathol 115:160-165

20. Spalenza V, Girolami F, Bevilacqua C, Riondato F, Rasero R, Nebbia C, Sacchi P, Martin P (2011) Identification of internal control genes for quantitative expression analysis by real-time PCR in bovine peripheral lymphocytes. Vet J 189:278-283

21. Rajarathnam K, Schnoor M, Richardson RM, Rajagopal S (2019) How do chemokines navigate neutrophils to the target site: dissecting the structural mechanisms and signaling pathways. Cell Signal 54:69-80

22. Lentini G, Famà A, Biondo C, Mohammadi N, Galbo R, Mancuso G, lannello D, Zummo S, Giardina M, De Gaetano GV, Teti G, Beninati C, Midiri A (2020) Neutrophils enhance their own influx to sites of bacterial infection via endosomal TLR-dependent Cxcl2 production. J Immunol 204:660-670

23. De Calisto J, Wang N, Wang G, Yigit B, Engel P, Terhorst C (2014) SAPdependent and -independent regulation of innate $T$ cell development involving SLAMF receptors. Front Immunol 5:186

24. Betz BC, Jordan-Williams KL, Wang C, Kang SG, Liao J, Logan MR, Kim CH, Taparowsky EJ (2010) Batf coordinates multiple aspects of B and T cell function required for normal antibody responses. J Exp Med 207:933-942

25. Iwasaki A, Medzhitov R (2015) Control of adaptive immunity by the innate immune system. Nat Immunol 16:343-353

26. Gondaira S, Higuchi H, Nishi K, Iwano H, Nagahata H (2017) Mycoplasma bovis escapes bovine neutrophil extracellular traps. Vet Microbiol 199:68-73

27. Mitiku F, Hartley CA, Sansom FM, Coombe JE, Mansell PD, Beggs DS, Browning GF (2018) The major membrane nuclease MnuA degrades neutrophil extracellular traps induced by Mycoplasma bovis. Vet Microbiol 218:13-19

28. Jenkins C, Samudrala R, Geary SJ, Djordjevic SP (2008) Structural and functional characterization of an organic hydroperoxide resistance protein from Mycoplasma gallisepticum. J Bacteriol 190:2206-2216

29. Machado CX, Pinto PM, Zaha A, Ferreira HB (2009) A peroxiredoxin from Mycoplasma hyopneumoniae with a possible role in $\mathrm{H}_{2} \mathrm{O}_{2}$ detoxification. Microbiology 155:3411-3419

30. Tatsiy O, McDonald PP (2018) Physiological stimuli induce PAD4-dependent, ROS-independent NETosis, with early and late events controlled by discrete signaling pathways. Front Immunol 9:2036

31. Rochael NC, Guimarães-Costa AB, Nascimento MT, DeSouza-Vieira TS, Oliveira MP, Garcia e Souza LF, Oliveira MF, Saraiva EM, (2015) Classical ROS-dependent and early/rapid ROS-independent release of neutrophil extracellular traps triggered by Leishmania parasites. Sci Rep 5:18302

32. Mulongo M, Prysliak T, Scruten E, Napper S, Perez-Casal J (2014) In vitro infection of bovine monocytes with Mycoplasma bovis delays apoptosis and suppresses production of gamma interferon and tumor necrosis factor alpha but not interleukin-10. Infect Immun 82:62-71

33. Maina T, Prysliak T, Perez-Casal J (2019) Mycoplasma bovis delay in apoptosis of macrophages is accompanied by increased expression of anti-apoptotic genes, reduced cytochrome $\mathrm{C}$ translocation and inhibition of DNA fragmentation. Vet Immunol Immunopathol 208:16-24

\section{Publisher's Note}

Springer Nature remains neutral with regard to jurisdictional claims in published maps and institutional affiliations. 